\title{
SUSTENTABILIDADE: RELAÇÃO ENTRE ESPAÇO URBANO E ENVELHECIMENTO ATIVO
}

SUSTAINABILITY: THE RELATIONSHIP BETWEEN URBAN SPACE AND ACTIVE AGING

SOSTENIBILIDAD: LA RELACIÓN ENTRE ESPACIO URBANO Y ENVEJECIMIENTO ACTIVO

Luzia Cristina Antoniossi Monteiro ${ }^{1}$

Marisa Silvana Zazzetta²

Miguel Etinger de Araujo Júnior ${ }^{3}$

1 Mestre e Doutora em Engenharia Urbana pela UFSCar. Professora Adjunta do Departamento de Gerontologia - UFSCar. Advogada. São Carlos/SP, Brasil. cristinaantoniossi4@gmail. com.

2 Mestre e Doutora em Serviço Social pela PUC/RS. Professora Adjunta do Departamento de Gerontologia - UFSCar. Assistente Social. São Carlos/SP, Brasil. marisazazzetta@yahoo. com

3 Doutor em Direto da Cidade pela UERJ, Professor Adjunto da UEL - Universidade Estadual de Londrina. Advogado. Londrina/PR, Brasil. miguel.etinger@gmail.com 
Resumo: O espaço urbano enfrenta o desafio de acolher de forma digna o exponencial número de idosos que as estatísticas apresentam para os próximos anos. Políticas públicas são imprescindíveis para promoção do envelhecimento ativo, garantia de sustentabilidade para cidadãos e cidades. O objetivo do trabalho foi demonstrar a relação entre envelhecimento populacional e espaço urbano sustentável. O estudo apresenta dois casos de participação de idosos na ressignificação do espaço urbano: Estratégia Cidade Amiga do Idoso (OMS) e Vila dos Idosos, aplicáveis em nível de cidades e em localidades, respectivamente. A metodologia consistiu em busca bibliográfica e investigação empírica na Vila dos Idosos. O espaço urbano sendo pensado a partir das novas necessidades e demandas geradas com o processo de envelhecimento e, incluindo a participação social, estará apto a promover o equilíbrio dinâmico entre as dimensões da sustentabilidade, tornando-se uma cidade para todas as idades.

Palavras-chave: Envelhecimento ativo. Sustentabilidade. Espaço urbano.

Abstract: The urban space faces the challenge of caring, in a dignified manner, for the exponential of number of elderly people that statistics have forecast for the coming years. Public policies are essential for promoting active aging, ensuring sustainability for cities and citizens. The aim of this study is to demonstrate the relationship between population aging and the urban development. It focuses on two cases involving elderly people in the reframing of the urban space: the Global Age-Friendly City Project (WHO) and "Vila dos Idosos" (Retirement village), which are applicable to cities and localities, respectively. The methodology consisted of a bibliographic search and empirical investigation at the "Vila dos Idosos". The urban spaces, considered from the new needs and demands generated through the aging process, and including social participation, will be able to promote the dynamic balance between the dimensions of sustainability, becoming a city for every age. 
Keywords: Active aging. Sustainability. Urban space.

Resumen: El espacio urbano enfrenta el reto de acoger de forma digna al exponencial número de ancianos que las estadísticas prevén para los próximos años. Las políticas públicas son imprescindibles para la promoción del envejecimiento activo, garantía de sostenibilidad para ciudadanos y ciudades. El objetivo del trabajo fue demostrar la relación entre envejecimiento poblacional y espacio urbano sostenible. El estudio presenta dos casos de participación de adultos mayores en la resignificación del espacio urbano: Estrategia Ciudad Amiga del Anciano (OMS) y Villa de los Ancianos, aplicables a nivel de ciudades y en localidades, respectivamente. La metodología consistió en búsqueda bibliográfica e investigación empírica en la Villa de los Ancianos. El espacio urbano pensado a partir de las nuevas necesidades y demandas generadas con el proceso de envejecimiento, e incluyendo la participación social, estará apto a promover el equilibrio dinámico entre las dimensiones de la sostenibilidad, transformándose en una ciudad para todas las edades.

Palabras clave: Envejecimiento activo. Sostenibilidad. Espacio urbano

INTRODUÇÃO

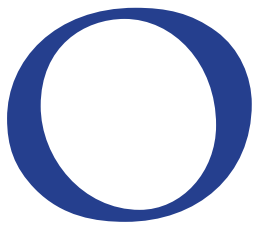

Brasil e o mundo têm enfrentado muitos desafios e novas demandas no que tange às temáticas: espaço urbano e envelhecimento. $\mathrm{O}$ mundo está envelhecendo e cerca de metade da humanidade vive hoje nas cidades 4 . As estimativas mundiais afirmam que o número de pessoas com 60 anos ou mais irá crescer 300\% em 50 anos, de 606 milhões no ano 2000, passará para quase 2 bilhões em 20505. Segundo a ONU (2014), os idosos são o grupo etário que mais cresce no mundo 6 .

4 ONU - ORGANIZAÇÃO DAS NAÇÕES UNIDAS. Rio + 20 Conferência das Nações Unidas sobre Desenvolvimento Sustentável. Disponível em: http://www.onu.org.br/rio20/ temas-cidades/. Acesso em: maio de 2013.

5 UNITED NATIONS. Population Division of the Department of Economic and Social Affairs. World population prospects: the 2002 revision. Highlights. New York: United Nations, 2003.

6 ONU - ORGANIZAÇÃO DAS NAÇÕES UNIDAS. Nova York, ONU discute desafios populacio- 
Se a maioria das pessoas mora e envelhece na área urbana, é preciso compreender e desvelar o direito de gozar e usufruir as funções sociais da cidade $^{7}$. Para determinados grupos, como o dos idosos, as dificuldades para garantir a integração socioespacial é ainda maior. Problemas financeiros e falta de moradia digna, aliados a fatores educacionais, culturais, étnicos, adensam para a heterogeneidade e geram conflitos urbanos e segregação social, principalmente nas grandes cidades 8 .

A Constituição Federal de $1988^{10}$, o Estatuto da Cidade (Lei 10.257/01) 11 e o Estatuto do Idoso (lei 10.741/03)12 são instrumentos que possibilitam implementar um espaço urbano que contemple a promoção do envelhecimento ativo e saudável, condição sine qua non para a almejada sustentabilidade. $\mathrm{O}$ meio ambiente ecologicamente equilibrado é imprescindível, sendo considerado "um novo direito humano fundamental, direcionado ao desfrute de adequadas condições de vida em um ambiente saudável"13 .

Práticas que propiciam a gestão democrática da cidade reforçam a concepção de desenvolvimento sustentável preconizado pelo Relatório Brundtland Commision ${ }^{14}$, concepção que será adotada neste estudo, e cujos contornos serão explicitados oportunamente. Se a longevidade humana será maior, a

nais do planeta, 20 anos após conferência sobre tema. Disponível em: http://www.onu. org.br/em-nova-york-onu-discute-desafios-populacionais-do-planeta-20-anos-apos-conferencia-sobre-tema/. Acesso em: jul-2014.

7 SILVA, José Afonso da. Direito Urbanístico brasileiro. São Paulo, Malheiros, 2006.

8 BONDUKI, Nabil. O modelo de desenvolvimento urbano de São Paulo precisa ser revertido. Disponível em: http://www.scielo.br/scielo.php?pid=S0103-40142011000100003\&script $=$ sci arttext. Acesso em: jul-2014

9 TEDESCHI Sebastian. Los conflictos urbanos en el territorio y el derecho en America Latina. In FERNANDES, Edésio, ALFONSIN, Betânia. Fórum de Direito Urbano e Ambiental. Belo Horizonte: Forum, 2010, pg 17,37, n. 54.

10 BRASIL. Constituição da República Federativa do Brasil de 1988. Disponível em: http://www.planalto.gov.br/ccivil_03/constituicao/constitui\%C3\%A7ao.htm. Acesso: out. 2012.

11 BRASIL. Lei no 10.257, de 10 de julho de 2001. Dispõe sobre o Estatuto da Cidade e dá outras providências. Disponível em: http://www.planalto.gov.br/ccivil 03/leis/leis 2001/ I10257.htm. Acesso em: mar. 2013.

12 BRASIL. Lei no 10.741, de 1 de outubro de 2003. Dispõe sobre o Estatuto do Idoso e dá outras providências. Disponível em: http://www.planalto.gov.br/ccivil_03/leis/2003/ I10.741.htm. Acesso em: mar. 2013

13 MILARÉ, Édis. Direito do ambiente. São Paulo: Revista dos Tribunais, 2009.

14 BRUNTDLAND, G. H. Our souls are tôo long for this short life. Sustainable Developmentinternational, London, 1999. Disponível em http:// www.sustedev.org. Acesso em: Nov 2012. 
tarefa de satisfazer as necessidades das presentes gerações, sem comprometer a capacidade das futuras satisfazerem suas próprias necessidades, envolverá outros desdobramentos, até então pouco enfrentados pelo Estado e pela sociedade. 0 envelhecimento bem-sucedido é um deles.

Para a organização Mundial da Saúde (OMS), envelhecimento ativo é "o processo de otimizar oportunidades para saúde, participação e segurança de modo a realçar a qualidade de vida na medida em que as pessoas envelhecem". A qualidade de vida é definida pela OMS como, "a percepção do indivíduo de sua posição na vida no contexto da cultura e sistema de valores nos quais ele vive e em relação aos seus objetivos, expectativas, padrões e preocupações"15.

Aqualidadedevidaé primordial para queas pessoas exercitem a sustentabilidade no espaço urbano onde vivem, sendo multifatorial e referendada a partir de dimensões como: relações sociais, meio ambiente, saúde (biopsicossocial), nível de independência (mobilidade, atividades da vida diária). Sustentabilidade, portanto, que permita alcançar e manter estas dimensões.

Uma cidade para todas as idades inicia-se com a inserção de políticas públicas que deem conta dessa nova realidade ${ }^{16}{ }^{17}$. Envolve um planejamento urbano integrado, diversos ramos do conhecimento, estudos multidisciplinares e interdisciplinares desenvolvidos para consolidar práticas e pactos formulados pela sociedade com a intervenção direta do poder público.

Ainda há tempo para traçar novas estratégias que direcionem esse ambiente urbano. No ano de 2013 houve um momento para discussão sobre a cidade inclusiva, com a realização das Conferências das Cidades (municipais, estaduais e nacionais), com o tema "Quem muda a cidade somos nós: Reforma Urbana já!"18, que é oportuno e adequado para discussão da temática tratada nesse trabalho.

15 ORGANIZAÇÃO MUNDIAL DA SAÚDE - OMS. Guia global das cidades amigas das pessoas idosas. 2009. Versão traduzida para o português. Disponível em: <http://whqlibdoc. who.int/publications/2007/9789899556867_por.pdf>. Acesso em: maio 2013.

16 ALFONSIN, Betânia de Moraes. In: MATTOS, Liana Portilho (Org.) Estatuto da Cidade Comentado. Belo Horizonte: Mandamentos, 2002.

17 MONTEIRO, L. C. A. Políticas Públicas Habitacionais Para Idosos: Um estudo Sobre os Condomínios Exclusivos. 2012. 145f. Tese (Doutorado em Engenharia Urbana) Programa de Pós Graduação em Engenharia Urbana UFSCar. Universidade Federal de São Carlos, São Carlos.

18 BRASIL. Ministério das Cidades. 5a Conferência Nacional das Cidades. Disponível em: http://www.cidades.gov.br/5conferencia/. Acesso em: maio 2013. 
Conforme o Guia Global Cidade Amiga do Idoso, elaborado pela Organização Mundial da Saúde, o mundo está envelhecendo rapidamente, e ao mesmo tempo "o nosso mundo é uma cidade em crescimento" ${ }^{19}$. Para que o espaço urbano se desenvolva de forma sustentável, as pessoas precisam estar ativas e saudáveis para serem protagonistas desta empreitada. Esse trabalho apresenta dois casos de práticas sustentáveis. A escolha dessas experiências se deu porque relacionam o desempenho de idosos ativos e sua participação social para minimizar a problemática vivenciada no espaço urbano.

O primeiro caso é a Estratégia Cidade Amiga do Idoso, da OMS, que teve início a partir da participação de 1500 idosos reunidos em grupos focais, realizados em 35 cidades, de 22 países. Os participantes elencaram fragilidades e potencialidades vivenciadas nos respectivos locais de residência, a partir dos quais foram traçados oito eixos considerados essenciais para melhoria da qualidade de vida. Esse projeto é aplicável às cidades que se comprometerem com políticas mais amigas dos idosos.

O segundo caso foi analisado à luz de investigação empírica na Vila dos Idosos, no bairro do Pari, na cidade de São Paulo, onde se buscou compreender a singularidade desse projeto, de moradia sustentável, construído após muita luta de pessoas reunidas em movimento social.

A articulação de políticas e projetos que envolvem diferentes âmbitos da vida das pessoas e do meio ambiente avançam rumo à sustentabilidade nas suas dimensões.

\section{A QUESTÃO DO IDOSO E DO ENVELHECIMENTO}

Segundo a Organização Mundial da Saúde (OMS), nos países desenvolvidos, o idoso é todo o indivíduo com idade igual ou superior a 65 anos; já nos países em desenvolvimento, são as pessoas com 60 anos ou mais. No Brasil, o idoso é a pessoa com idade igual ou superior a 60 anos, nos termos do artigo $1^{\circ}$ do Estatuto do Idoso. O mesmo diploma legal, no artigo $8^{\circ}$, garante o envelhecimento como direito 19 ONU- ORGANIZAÇÃO MUNDIAL DA SAÚDE - OMS. Guia global das cidades amigas das pessoas idosas. 2009. Versão traduzida para o português. Disponível em: <http://whqlibdoc.who.int/publications/2007/9789899556867_por.pdf>. Acesso em: maio 2013 
personalíssimo, reconhecendo-o como verdadeiro braço dos direitos sociais ${ }^{20}$.

Pinheiro ${ }^{21}$ afirma que o termo "idoso" parece ser o mais adequado, mas ressalta que há outras nomenclaturas utilizadas pelos doutrinadores e pela sociedade para designar a pessoa com 60 anos ou mais: "terceira idade", "velhos", "pessoa de meia-idade", "idade avançada", entre outras. Conforme Neri², "os idosos são populações ou indivíduos que podem assim ser categorizados em função da duração do seu ciclo vital". À medida que o ciclo de vida se alonga, aumenta a heterogeneidade entre as pessoas consideradas idosas. Para a autora, importantes elementos mesclam-se com a idade cronológica para determinar diferenças entre os idosos, como gênero, classe social, saúde, educação, fatores de personalidade, história passada e contexto sócio-histórico.

Desse modo, cada pessoa é única e a marca cronológica que a distingue das outras pessoas, em outras fases do ciclo vital, é suficiente apenas para delimitar fases, mas não basta para determinar, na prática, a condição biológica, social e psicológica de cada ser individualizado, dada a heterogeneidade.

Para Debert"23, a "padronização da infância, adolescência, idade adulta e velhice" pode ser pensada como resposta às mudanças estruturais na economia, antes, calcada na unidade doméstica; nos dias atuais, amparada no mercado de trabalho. Pelo processo de envelhecimento todos passam, sendo a velhice uma fase da vida. O idoso é o resultado final dessa combinação entre envelhecimento e velhice ${ }^{24}$.

20 Art. $8^{\circ} \mathrm{O}$ envelhecimento é um direito personalíssimo e a sua proteção um direito social, nos termos da legislação vigente.

21 PINHEIRO, Naide Maria. Estatuto do Idoso Comentado. Campinas: Servanda, 2008.

22 NERI, Anita Liberalesso. Idosos, velhice e envelhecimento. In: Neri, A. Palavras-chave em Gerontologia. 3. ed. Campinas, SP: Alínea, 2008. p. 114-115.

23 DEBERT, Guita Grin. A reinvenção da velhice. São Paulo: EDUSP, 1999, p. 51.

24 PAPALÉO NETO, M. O estudo da velhice: histórico, definição do campo e termos básicos. In: PAPALÉO NETO, M. Tratado de gerontologia. 2. ed. São Paulo: Editora Atheneu, 2007. P.29,38. 


\section{ENVELHECIMENTO POPULACIONAL NO BRASIL: INDICADORES PARA PROPULSIONAR A SUSTENTABILIDADE}

A marca de mais de 190 milhões da população brasileira alcançou a data de referência do Censo Demográfico (IBGE, 2010) ${ }^{25}$. A série de censos brasileiros mostra que a população experimentou sucessivos aumentos em seu contingente, tendo crescido quase vinte vezes desde o primeiro recenseamento realizado no Brasil, em 1872, quando tinha 9.930.478 de habitantes.

Entre 1980 e 2000 a população com 60 anos ou mais cresceu 7,3 milhões, totalizando mais de 14,5 milhões em 2000. Em 2012, a população idosa ultrapassou a marca de 24 milhões de pessoas ${ }^{26}$.

Em trinta anos, a população idosa no país dobrará de 7\% para 14\%. Paralelo ao processo de transição demográfica, o Brasil passa também pelo processo de transição epidemiológica, de forma diversa ao observado nos países desenvolvidos, com superposição entre as etapas, recrudescência de doenças (como dengue e febre amarela) e polarização epidemiológica.

Esse processo caracteriza-se pela diminuição da mortalidade por doenças transmissíveis, aumento da mortalidade por doenças não transmissíveis e por causas externas, com deslocamento da carga de morbi-mortalidade dos grupos mais jovens para os mais idosos e transformação de uma situação em que predomina a mortalidade para outra em que a morbidade é dominante.

A estrutura etária da população brasileira vem se modificando a partir da segunda metade do século XX. Houve declínio rápido dos níveis de mortalidade a partir da Segunda Guerra Mundial, seguido pela diminuição dos níveis de fecundidade, desde os anos 60, que se deu pelo uso eficaz dos métodos contraceptivos.

25 INSTITUTO BRASILEIRO DE GEOGRAFIA E ESTATÍSTICA - IBGE. Censo 2010: população do Brasil é de 190.732.694 pessoas. Disponível em: http://www.ibge.gov.br/home/ presidencia/noticias/noticia visualiza.php?id noticia=1766. Acesso em: maio 2012.

26 INSTITUTO BRASILEIRO DE GEOGRAFIA E ESTATÍSTICA - IBGE. Síntese de Indicadores Sociais. Uma análise das condições de vida da população brasileira. Disponível em: ftp:// ftp.ibge.gov.br/Indicadores_Sociais/Sintese_de_Indicadores_Sociais_2012/SIS_ _2012. pdf. Acesso em: maio- 2014. 
O IBGE, no ano de 2010, relata que a fecundidade no Brasil diminuiu ao longo dos anos basicamente como consequência das transformações ocorridas na sociedade brasileira, de modo geral, e na própria família, de maneira mais particular. Com isso, a fecundidade, em 1991, se posicionava em 2,89 filhos por mulher e, em 2000, em 2,38 filhos por mulher. Em 2010, o número médio de filhos nascidos vivos por mulher ao final de seu período fértil foi de 1,86 filhos. Ainda, de acordo com o IBGE, com base no conjunto de estimativas da fecundidade no Brasil, foi possível estabelecer a provável trajetória futura desta variável demográfica. Com os devidos ajustes inerentes ao processo de modelagem, a fecundidade limite brasileira seria de 1,5 filhos por mulher, valor que será alcançado entre 2027 e 2028.

Desta maneira, e considerando os dados do IBGE, o índice de envelhecimento aponta para mudanças na estrutura etária da população brasileira. Em 2010, para cada grupo de 100 crianças, de 0 a 14 anos, existe aproximadamente 31 idosos de 65 anos ou mais. Em 2050 o quadro muda, e para cada 100 crianças de 0 a 14 anos existirão aproximadamente 172 idosos.

As estruturas etárias projetadas mostram a transformação nas relações entre pessoas que ingressam (e permanecem) nas idades ativas e aquelas que atingem as chamadas idades potencialmente inativas. Em 2010, para cada pessoa com 65 anos ou mais de idade, aproximadamente 10 estavam na faixa etária chamada de potencialmente ativa (15 a 64 anos). Já em 2050, para cada pessoa com 65 anos ou mais de idade, pouco menos de 3 estarão na faixa etária potencialmente ativa.

No tocante às crianças e aos jovens, existirão cada vez mais pessoas em idade potencialmente ativa, "destinadas" a suprir suas necessidades. Essa realidade, que começa a se apresentar, tende a consolidar-se com o passar dos anos, requerendo da sociedade e do Estado práticas sustentáveis que atendam as novas e específicas demandas que surgirem ao longo da longevidade humana.

Neste momento, o Brasil passa pela chamada janela demográfica quando o número de pessoas com idades potencialmente ativas está em pleno processo de ascensão, e a razão de dependência total da população vem declinando em consequência da diminuição do peso das crianças de 0 a 14 anos sobre a população de 15 a 64 anos de idade. 
De acordo com o IBGE, no ano de 2010 a população com idade de ingresso no mercado de trabalho (15 a 24 anos) passa pelo número de 34.236 .06 milhões de pessoas, contingente que tende a diminuir nos próximos anos. $O$ aproveitamento dessa oportunidade (janela demográfica) proporcionaria o dinamismo e o crescimento econômico, desde que essas pessoas fossem preparadas em termos educacionais e de qualificação profissional para um mercado de trabalho cada vez mais competitivo não somente em nível nacional, mas também em escala global. Tal prática teria reflexo direto na cidade, impulsionando as dimensões da sustentabilidade e gerando um equilíbrio dinâmico entre o econômico, o social e, consequentemente, melhorando o ambiental.

Também constituem dados substanciais para a inserção de práticas realmente sustentáveis no espaço urbano a elevação da média de vida da população brasileira, alcançada com os avanços da medicina e as melhorias nas condições gerais de vida. A expectativa de vida ao nascer, que era de 45,5 anos de idade, em 1940, passa para 72,7 anos, em 2008, aumentando 27,2 anos de vida. Já em 2009, a expectativa de vida cresceu para 73,2 anos de vida, ou seja, de um ano para o outro, aumentou 0,31 anos (3 meses e 22 dias) e, entre 1980 e 2009, alta de 10,60 anos (10 anos, 7 meses e seis dias). Assim, ao longo de 29 anos, esse indicador teve um crescimento médio anual de 4 meses e 12 dias. E, segundo a projeção do IBGE (2008), a população no Brasil poderá chegar a 81,29 anos em 2050, basicamente o mesmo nível atual da Islândia (81,80), Hong Kong, China $(82,20)$ e Japão $(82,60)$.

A partir desses indicadores é possível afirmar que, para os próximos anos, o conceito de sustentabilidade dado pelo Relatório Brundtland Commision se aplicará mais às presentes gerações, já que essas irão viver mais tempo, acrescentando anos à sua trajetória de vida, do que às futuras gerações, tendo em vista a tendência decrescente do número de crianças e jovens na população total do país.

\section{SUSTENTABILIDADE: UMA CIDADE PARA TODAS AS IDADES}

Diversos estudos apontam concepções variáveis em relação à sustentabilidade e/ou ao desenvolvimento sustentável, fazendo distinções sobre esses termos, bem como ao que concerne à adoção de dimensões para a sustentabilidade. 
Sustentabilidade consiste, etimologicamente, na qualidade daquilo que é sustentável, do que seja passível de sustentação, manutenção. Sustentável, por sua vez, advém do latim "sustinere" (sub=abaixo + tenere=segurar, agarrar) e indica aguentar, suportar, sustentar.

O conteúdo da expressão sustentabilidade vem sendo cunhado ao longo do tempo e pode ser analisado sobre diversas áreas do conhecimento - ciências biológicas, exatas e sociais.

Alguns autores fazem expressa referência às distinções das expressões "sustentabilidade" e "desenvolvimento sustentável".

Veiga ${ }^{27}$ afirma que a expressão "desenvolvimento sustentável" é utilizada atualmente em torno da ideia vaga de durabilidade, mas que teria surgido do fato de não se aceitar como uma fatalidade que o desenvolvimento e a conservação da natureza pudessem ser antagônicos. Para o autor, esta expressão referia-se ao que se pode chamar agora de sustentabilidade ambiental do processo de desenvolvimento. Há posicionamentos em que o desenvolvimento sustentável é compreendido como o meio para o alcance da sustentabilidade, sendo essa o fim.

As diferenças entre sustentabilidade e desenvolvimento sustentável afloram não como uma questão dicotômica, mas como um processo em que o primeiro se relaciona com o fim, ou objetivo maior; e o segundo como meio. Todavia, esta distinção está imersa em uma discussão ideológica que se insere em pensar algo para o futuro ou em se preocupar com ações presentes e impacto futuro.

O foco principal, ao se discursar e se preocupar com a sustentabilidade, está na vinculação do tema ao lugar a que se pretende chegar; enquanto com o desenvolvimento o foco está em como se pretende chegar.

(...) o presente para o processo de desenvolvimento e o futuro para a sustentabilidade. São noções, na realidade, não contraditórias, mas complementares e fundamentais para posicionar os grupos de discussão ${ }^{28}$.

27 VEIGA, José Eli da. Sustentabilidade: a legitimação de um novo valor. São Paulo: Editora SENAC, 2010.

28 MENDES, Judas Tadeu Grassi. SILVA, Christian Luiz da. Reflexões sobre o desenvolvimento sustentável: agentes e interações sob a ótica multidisciplinar. Petrópolis: Vozes, 
Esse trabalho, por questões metodológicas, se detém ao conceito de desenvolvimento sustentável preconizado pelo Relatório Brundtland Commision e adota as dimensões ambiental, social e econômica. Para Nobre (1999), este conceito tem duas etapas estratégicas nítidas em busca de sua institucionalização, a primeira consiste em elevar a problemática ambiental ao primeiro plano da agenda política internacional, e a segunda diz respeito à inserção das questões ambientais na formulação e na implementação de políticas públicas.

Tal opção se dá em função do recorte que é dado para as gerações presentes, em especial, parte da população que alcançou a classificação de idoso e que, em função do comprovado aumento da expectativa de vida nos últimos anos, exige um estudo dos mecanismos utilizados atualmente (meios - desenvolvimento sustentável), para a consolidação de um modelo que seja justo e legítimo com esta parcela da população (fim - sustentável).

Ademais, valoriza-se esta concepção de desenvolvimento sustentável em função da afirmação da própria Gro Harlem Brundtland, então presidente da Comissão Mundial sobre Meio Ambiente de Desenvolvimento, que durante a Assembleia Geral da ONU no ano de 1987 caracterizou este desenvolvimento com um "conceito político" e um "conceito amplo para o progresso econômico e social"29. E são algumas políticas voltadas para o atendimento ao idoso que serão analisadas neste trabalho.

A sustentabilidade, principalmente sob a perspectiva da preservação do meio ambiente, vem sendo discutida há muitos anos. Com efeito, a questão do desenvolvimento sustentável, traduzida na utilização dos recursos naturais de forma a preservar um meio ambiente equilibrado para as presentes e as futuras gerações, ganhou relevância mundial, principalmente levando-se em consideração a incorporação do viés ambiental ao mercado de consumo, conferindo-lhe especial relevância como fator a ser incorporado a determinado produto de forma a valorizá-lo junto a este mercado.

A Organização das Nações Unidas (ONU) criou o Índice de Desenvolvimento 2005. p. 13.

29 Brundtland Gro Harlem, apud VEIGA, José Eli da. Sustentabilidade: a legitimação de um novo valor. São Paulo: Editora SENAC, 2010, p. 113. 
Humano (IDH), tomando como base fatores extra-econômicos para determinar o grau de desenvolvimento de uma sociedade ${ }^{30}$. Amartya Sen, que juntamente com Mahbub ul Haq participou do processo de criação do IDH da ONU, alerta para o fato de que o desenvolvimento vai muito além de crescimento ou de variáveis relacionadas à renda, estando vinculado "com a melhoria da vida que levamos e das liberdades que desfrutamos"31. O desenvolvimento "é um processo de expansão das liberdades substantivas das pessoas" 32.

A partir de todos estes esforços internacionais, bem como do programa de implementação da Agenda 21, da Declaração do Rio, das contribuições derivadas da Habitat II, realizada em 1996 em Istambul, e da reafirmação destes compromissos durante a Cúpula Mundial sobre Desenvolvimento Sustentável em Johanesburgo (Rio + 10) no ano de 2002, passou-se a adotar um conceito de sustentabilidade ampliada. Esta ideia reside na indissociabilidade entre os fatores sociais e ambientais e na necessidade de que a degradação do meio ambiente seja enfrentada juntamente com o problema mundial da pobreza. É a união entre a Agenda Ambiental e a Agenda Social (ou Agenda Verde e Agenda Marrom).

O direito à cidade ${ }^{33}$ inerente a todo e qualquer cidadão está intrinsecamente relacionado às questões da sustentabilidade, uma vez que é no espaço urbano em que se estabelecem as inter-relações entre cidadãos e meio ambiente natural e o construído.

30 ONU - ORGANIZAÇÃO DAS NAÇÕES UNIDAS / PNUD - PROGRAMA DAS NAÇÕES UNIDAS PARA O DESENVOLVIMENTO. Desenvolvimento humano e IDH. Disponível em: <http:// www.pnud.org.br/idh/>. Acesso em: 19 ago 2011.

31 SEN, Amartya. Desenvolvimento com liberdade. Tradução de Laura Teixeira Motta. São Paulo: Companhia das Letras, 2000, p. 28.

32 SEN, Amartya. Desenvolvimento com liberdade. Tradução de Laura Teixeira Motta. São Paulo: Companhia das Letras, 2000, p. 336.

33 O "direito à cidade" pode ser caracterizado nos termos do artigo I.2 da Carta Mundial pelo Direito à Cidade, redigido por diversas organizações ao redor do mundo, como: "O Direito a Cidade é definido como o usufruto eqüitativo das cidades dentro dos princípios de sustentabilidade, democracia e justiça social; é um direito que confere legitimidade à ação e organização, baseado em seus usos e costumes, com o objetivo de alcançar o pleno exercício do direito a um padrão de vida adequado. O Direito à Cidade é interdependente a todos os direitos humanos internacionalmente reconhecidos, concebidos integralmente e inclui os direitos civis, políticos, econômicos, sociais, culturais e ambientais Inclui também o direito a liberdade de reunião e organização, o respeito às minorias e à pluralidade ética, racial, sexual e cultural; o respeito aos imigrantes e a garantia da preservação e herança histórica e cultural". 
A legislação internacional e a brasileira estampam normas que regulamentam esse direito. A legislação urbanística da Espanha ${ }^{34}$ determina que dez por cento (10\%) dos loteamentos devem atender às demandas habitacionais sociais. Até a crise econômica deflagrada em 2008 os espanhóis consideravam a problemática habitacional como uma de suas prioridades. Por conta disso, fortes movimentos sociais engajados na questão habitacional surgiram em diversos momentos diferentes da política espanhola. ${ }^{35} \mathrm{Na}$ França a loi relative à solidarité et au renouvellement urbains ${ }^{36}$ define uma meta de, pelo menos, $20 \%$ para habitação social nas cidades com mais de 50 mil habitantes. Em países da América Latina, como no Chile, embora exista um avanço paulatino no sentido de implementar uma cidade mais justa e equitativa a partir do direito urbanístico, há o enfrentamento de alguns problemas, por exemplo escassez do solo ${ }^{37}$.

No Brasil, a Constituição Federal de 1988, não por acaso chamada "Constituição Cidadã", embora apresente um resquício do modo patrimonialista de produção das cidades, em grande parte do seu texto traz marcas das lutas sociais, movimentos engajados nas questões urbanas, como o Movimento Nacional pela Reforma Urbana (MNRU).

Os movimentos sociais, principalmente os de moradia, são responsáveis pela introdução de artigos na Constituição que determinam o desenvolvimento

34 ESPANHA. Lei 39 de 14 de dezembro de 2006. Dispõe, de Promoción de la Autonomía Personal y Atención a las personas en situación de dependencia. ESPANHA, Lei 01 de 26 de julho de 2005. Por el que se aprueba el texto refundido de La ley de Urbanismo.

35 LA PUERTA, Belén Morata García. Cuestiones para investigación: ¿qué pasa con los servicios sociales en España? Serviço Social e Sociedade. no.108. São Paulo Oct./Dec. 2011. Disponível em: <http://www.scielo.br/scielo.php?pid=S0101-6282011000400002\&script $=$ sci_abstract\&tlng=pt $>$. Acesso em: jul. 2012.

SEN, Amartya. Desenvolvimento com liberdade. Tradução de Laura Teixeira Motta. São Paulo: Companhia das Letras, 2000, p. 336.

36 FRANCE, Conceil National des politiques de lute contre La pauvreté et I'exclusion sociale. Loi 2000-1208 du 14 décembre 2000 relative à la solidarité et au renouvellement urbain (SRU). Disponível em: http://www.cnle.gouv.fr/Loi-2000-1208-du-14-decembre-2000. html. Acesso em: jun-2014.

SEN, Amartya. Desenvolvimento com liberdade. Tradução de Laura Teixeira Motta. São Paulo: Companhia das Letras, 2000, p. 336.

37 MOSLER Enrique Rajevic. El palatino pero insuficiente desarollo Del Derecho urbanístico em Chile: em tánsito de La adolescência a La madureza. In: FERNANDES, Edésio, ALFONSIN, Betânia.

Fórum de Direito Urbano e Ambiental. Belo Horizonte: Forum, 2010, pg 61,70, n. 54.

SEN, Amartya. Desenvolvimento com liberdade. Tradução de Laura Teixeira Motta. São Paulo: Companhia das Letras, 2000, p. 336. 
sustentável a cargo do Estado, da sociedade e, principalmente, do município, observando-se o cumprimento das funções sociais da cidade. A redação do artigo 182 é expressa ao afirmar que:

A política de desenvolvimento urbano, executada pelo Poder Público municipal, conforme diretrizes gerais fixadas em lei, tem por objetivo ordenar o pleno desenvolvimento das funções sociais da cidade e garantir o bem- estar de seus habitantes ${ }^{38}$.

Além desse, outros artigos da Carta da República explicitam princípios para a gestão democrática da cidade. Objetivos fundamentais para a construção da sociedade brasileira estão explícitos no artigo 30: construir uma sociedade livre, justa e solidária; garantir o desenvolvimento nacional; erradicar a pobreza e a marginalização e reduzir as desigualdades sociais e regionais; e promover o bem de todos, sem preconceitos de origem, raça, sexo, cor, idade e quaisquer outras formas de discriminação.

Além da legislação vigente, os Tribunais Superiores, há algum tempo, vêm decidindo de acordo com a função social da propriedade ${ }^{39}$. Nesse sentido, no ano de 1998, o agravo de instrumento ${ }^{40}$ do Tribunal de Justiça do Rio Grande do Sul já reconhecia, por maioria de votos, a função social da propriedade em ação de reintegração de posse. O Desembargador Guinther Spode desconsiderou,

38 BRASIL. Constituição da República Federativa do Brasil de 1988. Disponível em: <http://www.planalto.gov.br/ccivil_03/constituicao/constitui\%C3\%A7ao.htm> Acesso: out. 2012.

39 AGRAVO DE INSTRUMENTO - Reintegração de posse. Insurgência do Município de São Paulo contra a determinação do Juízo de origem, que condicionou sejam adotados, pela exequente, os meios necessários para abrigar as crianças deficientes e portadoras de Síndrome de Down, que estão alojadas em pequena e insignificante área pública, como condição para a efetivação da ordem de reintegração na sua posse. Decisão mantida. Recurso não provido. "O Estado não é - e não pode ser - um fim em si mesmo. Também não se admite que esse mesmo Estado coloque a propriedade de bens públicos com valor que supere a vida humana e o bem-estar das pessoas que Ihe outorgaram a prerrogativa de as proteger. Ademais, a invasão de terras improdutivas ou não aproveitadas convenientemente ou a ocupação de 'sobras' mal utilizadas ou não utilizadas pelo Poder Público, por parte de pessoas doentes e desamparadas, está a revelar um desacerto social, um desvio de rumo e um indício de que alguma coisa não vai muito bem na distribuição de renda e no cumprimento dos objetivos do Estado, estabelecidos expressamente na Constituição Federal." (TJSP - 3a Câm. de Direito Público; AI no 335.347-5/0-00-SP; Rel. Des. Rui Stoco; j. 21/10/2003; v.u.).

40 AGRAVO DE INSTTRUMENTO. Disponível em: <http://www.pge.sp.gov.br/centrodeestudos/bibliotecavirtual/dh/volume\%20ii/agravo598360402 .htm> e http://www.tjrs.jus.br. Acesso em: 14/02/14. 
em razão do interesse tutelado, uma falha processual e recebeu o recurso, fundamentando que "o feito que deu origem à decisão agravada, sem dúvida, versa sobre direitos fundamentais do homem, tratando-se, portanto, de demanda incomum", concluindo que, "diante desta singularidade, penso não ser possível mantermo-nos presos às amarras da legislação, especialmente da processual que é apenas veículo para se chegar à melhor decisão. Por melhor decisão, deve-se entender, é óbvio, a mais justa".

Eventos como a Conferência Nacional das Cidades, realizada no ano de 2013, também abarcam reflexões sobre as demandas atuais e retomam questões que fundamentam a luta por uma sociedade atenta às problemáticas sociais e na gestão democrática da cidade. Discussões essas iniciadas na década de 1970, com a realização do I Seminário da Reforma Urbana, assunto adormecido na época da ditadura militar e restaurado nos anos de 1980 pelos movimentos sociais engajados. As demandas sociais reivindicadas pelos movimentos sociais consolidaram-se na minuta de emenda da reforma urbana na Assembleia Nacional Constituinte (1986), traduzidas na expressão do princípio da função social da propriedade e da cidade estampados na Constituição Federal de 1988.

$\mathrm{Na} 5^{a}$ Conferência Nacional das Cidades, agruparam-se propostas de prioridades para o Ministério das Cidades, relativas ao saneamento ambiental; mobilidade urbana e trânsito; capacitação e assistência técnica; financiamento da política urbana; participação, controle social e conselhos; política territorial e regularização fundiária e habitação ${ }^{41}$. Essas propostas podem funcionar como embasamento teórico para implementação de políticas públicas que minimizem as desigualdades sociais nas cidades brasileiras. Nesse sentido, são gerados "territórios de pertencimento"42 que tragam dignidade para os cidadãos idosos, integrando-os socioespacialmente.

$415^{a}$ Conferência Nacional das Cidades. Propostas de prioridades para o Ministério das Cidades. Disponível em: http://www.cidades.gov.br/5conferencia/images/arquivos/propostas-prioridades-MCID.pdf. Acesso em: jul-2014.

42 FRANÇA, Fo. Genauto Carvalho; SANTANA Jr., Gildásio. Economia Solidária e Desenvolvimento Local: uma contribuição para redefinição da noção de sustentabilidade a partir da análise de três casos na Bahia. Disponível em: http://ites.colivre.net/pub/Site/ Publicacao4/07genautolocal.pdf. Acesso em: nov. 2010. 
Para Fernadez"43, "diminuir as desigualdades e melhorar a qualidade de vida das pessoas são objetivos não só muito mais nobres como muito mais sustentáveis que o aumento do PIB".

Segundo Acselrad ${ }^{44}$, pensar na sustentabilidade significa, dentre outras, "pensar um novo modelo de desenvolvimento urbano, baseado nos princípios de democratização dos territórios, combate à segregação socioespacial, na defesa dos direitos de acesso aos serviços urbanos e na superação da desigualdade".

A resolução dessa problemática em relação à população idosa, segundo a Constituição Federal, é de responsabilidade da família, da sociedade e do Estado nos termos do artigo 230: "A família, a sociedade e o Estado têm o dever de amparar as pessoas idosas, assegurando sua participação na comunidade, defendendo sua dignidade e bem-estar e garantindo-lhes o direito à vida".

OEstatuto doIdoso reitera esse dever, além dededicarumcapítuloespecialmente à proteção dos direitos difusos individuais indisponíveis ou homogêneos (artigos 78 a 92). Já o Estatuto da Cidade estabelece as diretrizes e os instrumentos que oportunizam a consolidação do direito à cidade. Ambos, Estatuto da Cidade e Estatuto do Idoso, constituem marcos regulatórios imprescindíveis para o alcance do direito à cidade aos idosos, pois estabelecem o cumprimento de suas funções sociais. E, afinal, ter função social é próprio da cidade.

Além das questões ligadas aos direitos difusos, um grande desafio para implementar cidades sustentáveis é a questão da moradia digna. Um estudo de Lofqvist et al. ${ }^{45}$ mostra que a troca de residência para pessoas muito idosas tem aspectos contraditórios e influencia suas emoções, apontando a ligação que existe entre a pessoa e o local de moradia. Portanto essa população necessita de segurança e sensação de pertencimento ao local que habita. Situação que pode ser possibilitada, segundo o próprio Estatuto da Cidade na diretriz que visa

43 FERNANDEZ, Fernando. Aprendendo a lição de Chaco Canyon. Revista Reflexão, Instituto Ethos, São Paulo, 2001. p.55.

44 ACSELRAD, Henri. A duração das cidades: sustentabilidade e riscos nas políticas públicas. Rio de Janeiro, 2001.p. 23.

45 LOFQVIST, Charlotte; GRANBOM, Marianne; HIMMELSBACH, Ines; IWARSSON, Susanne; OSWALD, Frank; HAAK, Maria. Voices on relocation and aging in place in very old age - a complex and ambivalent matter. The Gerontologist. V. 53, no.6, p. 919-927, 2013. 
corrigir distorções do crescimento urbano e seus efeitos negativos sobre o meio ambiente (artigo, $2^{\circ}$, inciso IV).

A moradia digna é direito social estampado no artigo $6^{\circ}$ da Constituição Federal, reconhecido internacionalmente pela Declaração Universal dos Direitos Humanos (1948) e ratificada no Pacto Internacional dos Direitos Sociais, Econômicos e Culturais (1966), artigo 11 , item $1^{46}$. O Comentário Geral $4^{47}$ analisa o conteúdo do artigo citado, dedicado ao direito a uma habitação condigna.

O Estatuto do Idoso afirma no artigo 37 que o idoso tem direito à moradia digna. Mais aprofundado, o artigo 38 explicita que nos programas habitacionais públicos ou subsidiados com recursos públicos pessoas com mais de 60 anos gozam de prioridade na aquisição de imóvel para moradia própria, com reserva de pelo menos três por cento (3\%) das unidades habitacionais ${ }^{48}$. O Estatuto da Cidade na diretriz ditada pelo artigo $2^{\circ}$, inciso I, propulsiona a aplicabilidade da lei:

(...) garantia do direito a cidades sustentáveis, entendido como o direito à terra urbana, à moradia, ao saneamento ambiental, à infra-estrutura urbana, ao transporte e aos serviços públicos, ao trabalho e ao lazer, para as presentes e futuras gerações.

No mesmo sentido ainda, há harmonização dos Estatutos da Cidade e do Idoso, uma vez que o Estatuto da Cidade, no artigo $2^{\circ}$, inciso $\mathrm{V}$, apresenta como diretriz a oferta de equipamentos urbanos e comunitários, transporte e serviços públicos adequados aos interesses e às necessidades da população e às características locais. E o Estatuto do Idoso se refere à implantação de equipamentos urbanos comunitários voltados ao idoso e à eliminação de barreiras arquitetônicas e urbanísticas, para garantia de acessibilidade (redação do artigo 38, III). Destacase, ainda, o Estatuto da Cidade, propiciando a utilização de instrumentos de 46 Os Estados Partes do presente Pacto reconhecem o direito de toda pessoa em nível de vida adequado para si próprio e sua família, inclusive à alimentação, à vestimenta e à moradia adequadas, assim como a uma melhoria contínua de suas condições de vida.

47 O Comentário Geral 4 é um dos comentários elaborados pelo Comitê dos Direitos Econômicos, Sociais e Culturais, um dos órgãos das Nações Unidas para o controle dos Tratados em matéria de Direitos Humanos.

48 A redação do artigo 38 do Estatuto do Idoso, alterado pela Lei $12.418 / 11$, infere a possibilidade de disponibilizar uma cota ainda maior que $3 \%$ para pessoas idosas nos empreendimentos habitacionais construídos com dinheiro público. No Estado de São Paulo a Companhia de Desenvolvimento Habitacional e Urbano (CDHU) pratica a reserva de cotas de $5 \%$ para idosos. 
política urbana, como os de planejamento municipal (artigo $4^{\circ}$, inciso III), para viabilizarem a conquista da moradia digna, e em especial nos casos em que idosos se mobilizam em movimentos sociais reivindicatórios para alcance dos seus direitos. Bom exemplo nesse sentido é a Vila dos Idosos, cujo projeto e execução ocorreram por meio do protagonismo das pessoas com mais de 60 anos reunidas em movimento social e das ações do poder público, possibilitando a gestão democrática (artigo $2^{\circ}$, inciso II do Estatuto da Cidade).

A participação de idosos em movimentos sociais legitima a aplicabilidade dos instrumentos do Estatuto da Cidade e pode proporcionar a dignidade do morar alcançando a mobilidade e a acessibilidade desejáveis em um espaço urbano digno e equitativo.

A metodologia adotada pela Estratégia Cidade Amiga do Idoso deve ser inserida no planejamento de cidades, em especial, em áreas definidas pelo plano diretor, de acordo com o que preconiza os Estatutos da Cidade e do Idoso, tendência ao bem-estar da população e o envelhecimento bem-sucedido.

\section{SUSTENTABILIDADE E ESTRATÉGIA CIDADE AMIGA DO IDOSO}

A relação entre envelhecimento populacional e ambiente urbano sustentável será mais forte se fundamentada na promoção do envelhecimento ativo. Se as pessoas estão vivendo mais tempo, precisam inserir-se e participar ativamente da construção da cidade para todas as idades. A Organização Mundial da Saúde (OMS) teve importante iniciativa em 2008, com o lançamento da estratégia Cidade Amiga do Idoso, iniciada após realização de pesquisa feita com grupos focais envolvendo 1500 idosos, em 35 cidades, de 22 países. No Brasil, o projeto piloto foi desenvolvido no bairro de Copacabana, Rio de Janeiro.

Os entrevistados discorreram sobre aspectos positivos e negativos, em relação a oito eixos referentes aos seus respectivos locais de moradia. A partir das entrevistas com os idosos, a OMS criou o Guia Global da Cidade Amiga do Idoso, com o objetivo de ajudar as cidades a se autoavaliarem e identificarem, sob a ótica dos entrevistados, onde e como elas podem ser mais amigas dos idosos. 
Com vistas às oitivas, uma listagem foi desenvolvida em relação a cada área da vida urbana, apontando as vantagens e as dificuldades enfrentadas pelos idosos em ambientes públicos e privados, visando alcançar melhorias significativas para cada localidade.

A cidade que adere à metodologia preconizada pelo Projeto traduz-se, ainda de que forma paulatina, em uma cidade sustentável à medida que propicia o envelhecimento ativo, melhorando a qualidade de vida. Propulsiona, ainda, a implementação de políticas, serviços, ambientes e estruturas de apoio para a população idosa.

Os eixos identificados como essenciais para a melhoria da vida na cidade são: espaços exteriores e edifícios; transportes; moradia; participação social; respeito e inclusão social; participação cívica e emprego; comunicação e informação; apoio da comunidade e serviços de saúde. Dentre os oito eixos, o prioritário é a moradia digna, por consistir um direito fundamental do cidadão.

Seja idoso ou não, o ser humano encontra no local onde mora condições de segurança e bem-estar diretamente relacionadas à qualidade de vida. A moradia propicia, ainda, o acesso aos serviços comunitários e sociais, favorecendo aspectos subjetivos, como respeito, integração e participação, determinantes para a concretização do direito ao espaço urbano.

A casa, além de representar um teto, o local onde se restauram forças, guarda aspectos íntimos e particulares, representando o "ninho", o pertencimento ao território e agasalha a identidade de cada ser.

Nesse sentido, Prado e Perracini afirmam que:

é importante definir que o que caracteriza lar não é somente o ambiente físico mas, especialmente, as preferências colocadas em cada espaço na forma de objetos, do design, das atividades desenvolvidas, dos relacionamentos estabelecidos e da funcioncalidade". 49

Nesse sentido, diversificar as modalidades habitacionais é importante para atender a heterogeneidade da população, que varia de idoso para idoso

49 PRADO, Adriana Romeiro de Almeida; PERRACINI, Monica Rodrigues. A construção de ambientes favoráveis aos idosos. In: NERI, A. Qualidade de vida na velhice. Campinas: Alínea, 2011, p. 220 
considerando os contextos culturais, étnicos e as localidades onde estão inseridos.

O Guia Global Cidade Amiga do Idoso apresenta um checklist para alcançar moradias amigáveis dos idosos, envolvendo aspectos como custo acessível, serviços essenciais, planejamento, modificações, manutenção, possibilidade de envelhecer em casa, diversidade de tipologias habitacionais, integração comunitária e ambiente da casa.

Moradias adequadas às necessidades pessoais refletem uma experiência positiva do envelhecer, propulsionam a acessibilidade, que atualmente contempla a abrangência de "novas dimensões que envolvem importantes aspectos do diaa-dia das pessoas, tais como rotinas das atividades e serviços, além de programas e políticas governamentais e institucionais" 50 .

Agarantia da acessibilidade em todas as dimensões se coaduna intrinsecamente com as dimensões da sustentabilidade, indispensável para consubstanciar a integração dos idosos no espaço urbano. Políticas públicas são imprescindiveis para esse fim.

Acessibilidade e sustentabilidade são expressões que estão intrinsicamente ligadas à ideia de liberdade. E existem diferentes formas de liberdade, combatendo privações, opressões, etc., em um mundo marcado por opulência. O combate aos problemas do mundo, nesta época, exige a liberdade individual como comprometimento social. Para Sem ${ }^{51}$, a expressão da liberdade é tanto fim como meio para o desenvolvimento. Consiste na eliminação de tudo o que limita as escolhas e as oportunidades das pessoas. Tratar de forma adequada a questão da acessibilidade é não impor privações ao idoso, portanto, não impor dificuldades para o alcance da felicidade.

Desde o lançamento da Cidade Amiga do Idoso, diversas cidades pelo Brasil e pelo mundo vêm aderindo ao Projeto. O estado de São Paulo lançou, em maio

50 SÃO PAULO (Estado). Ministério Público. Guia Prático: o direito de todos à educação: diálogo com os Promotores de Justiça do Estado de São Paulo/ Ministério Público do Estado de São Paulo. São Paulo: MP, 2011. 165 p.

51 SEN, Amartya K. Por que é necessário preservar a coruja-pintada. Folha de São Paulo, 14 de março de 2004. Disponível em: http://www1.folha.uol.com.br/folha/ciencia/ ult306u11316.shtml. Acesso em: mar. 2013. 
de 2012, o programa "São Paulo Amigo do Idoso". Considerando as dificuldades encontradas para a implementação dos oito eixos, de forma geral, tem-se optado por implementar bairros, ruas ou locais amigos dos idosos. Importa que o Projeto seja inserido nos respectivos planos diretores, ainda que as ações estejam por se iniciar, ao menos a temática passa a integrar o (re)planejamento da cidade com práticas sustentáveis em determinadas localidades.

Concomitante ao nascimento do Projeto Cidade Amiga do Idoso, no ano de 2007, pessoas idosas de São Paulo, reunidas em movimento social por moradia digna, inauguravam uma política habitacional com ênfase em práticas sustentáveis no que tange a aspectos sociais, econômicos e ambientais.

\section{A VILA DOS IDOSOS: EXEMPLO DE SUSTENTABILIDADE EM POLÍTICAS PÚBLICAS HABITACIONAIS}

A relação entre envelhecimento populacional e ambiente urbano sustentável se evidencia em exemplos de participação social efetiva, como acontece no Grupo de Articulação para Moradia do Idoso da Capital (GARMIC), que, após anos de luta por moradia digna, mobilizando a sociedade e o poder público, conquista a Vila dos Idosos, no bairro do Pari, na cidade de São Paulo.

O Pari é um bairro antigo, localizado a nordeste do centro histórico da capital. É uma localidade plana e baixa ocupando a várzea do Rio Tietê. Os prédios do Pari raramente passam de três andares, há muitos galpões e estacionamentos de ônibus no bairro. O Quadro 1 apresenta a população, destacando-se as faixas etárias acima de 60 anos na cidade de São Paulo, segundo dados do IBGE (2010), bem como representa a demanda por moradia de idosos de baixa renda cadastrados na prefeitura, no ano de 2007, época da inauguração da Vila. 
Quadro 1 - População de São Paulo e demanda por moradia digna de idosos

\begin{tabular}{|l|l|}
\hline Descrição & Valor \\
\hline População total & 11253503 \\
\hline Homens com idade maior que 60 anos & $4.76 \%$ \\
\hline Mulheres com idade maior que 60 anos & $7.12 \%$ \\
\hline Demanda por moradia para idosos de baixa renda (2007) & 5000 \\
\hline
\end{tabular}

Fonte: Dados IBGE, 2010 e GARMIC, 2007. Elaboração Monteiro (2012).

A Vila dos Idosos é fruto de um trabalho engajado, iniciado em 1999 pelo GARMIC. O Grupo desenvolve e realiza projetos com idosos filiados ao movimento social e tem como meta buscar junto ao poder público e instituições da sociedade civil a criação de políticas públicas habitacionais para a população idosa de baixa renda na cidade de São Paulo.

Por suas iniciativas, o GARMIC conseguiu ainda que outras unidades habitacionais, em diferentes conjuntos populares, fossem destinadas aos idosos da capital paulista. Além disso, o grupo também realiza ações de cunho social e assistencial, como participação em fóruns e em conselhos municipais.

O conjunto habitacional foi construído em terreno de propriedade da prefeitura de São Paulo, que há muito tempo estava ocioso. Nesse sentido, por meio da articulação, GARMIC e poder público municipal, efetivou-se o princípio da função social da propriedade. Sem dúvida, um caso em que prevalece a sustentabilidade retratada no uso e na ocupação adequados do solo urbano.

Pouco tempo após a inauguração, a Vila foi reconhecida como iniciativa em políticas públicas sustentáveis e melhores experiências em gestão local, no âmbito brasileiro, prêmio concedido pela Caixa Federal. Segundo critérios do concurso, a Vila está de acordo com o preconizado pela Agenda Habitat na categoria projetos de sustentabilidade e combate à pobreza.

Grande parte das 145 unidades habitacionais da Vila dos Idosos é adaptada às necessidades dos idosos, contribuindo para a preservação da autonomia e independência dos moradores, fato que colaborou para a sua premiação e o seu reconhecimento público. 
Em relação ao projeto arquitetônico, a Vila compõe-se de 3 pavimentos, formados por 48 apartamentos de $43 \mathrm{~m}^{2}$ e 72 quitinetes de $29 \mathrm{~m}^{2}$. Possui 3 elevadores e área de circulação ampla para cadeiras de rodas. O convívio social também é garantido na quadra de bochas, em espaços amplos do salão de festas, na sala de atividades e nos corredores. Um diferencial importante da Vila dos Idosos é a Biblioteca Municipal Adelpha Figueiredo, localizada junto ao conjunto.

Considerando as dimensões da sustentabilidade, tem-se que a Vila dos Idosos atende as dimensões social, ambiental e econômica.

Sobre a dimensão ambiental, verificam-se duas concepções apontadas por Sachs ${ }^{52}$ : "os sistemas de sustentação da vida como provedores de recursos e como 'recipientes' para a disposição de resíduos", e a Vila possibilitando o uso e a ocupação do solo, cumprindo uma função social da cidade. O uso adequado do imóvel para moradia digna é mais sustentável do que um terreno ocioso, situação em que se encontrava o imóvel anteriormente à construção das casas. Ainda do ponto de vista ambiental, a sustentabilidade está presente na horta comunitária, no espelho d'água implantado sobre caixa de retenção de águas pluviais, áreas verdes, características especiais do local, inseridas no próprio projeto arquitetônico.

Em relação à dimensão econômica, considerada como "conditio sine qua non para que as coisas aconteçam" ${ }^{23}$, há de destacar-se o equilíbrio existente entre a renda do morador e o custo da moradia. Assim, os residentes arcam com o pagamento de um valor mensal variável entre $10 \%$ e $15 \%$ de sua renda familiar.

Essa é uma modalidade de pagamento denominada Programa de Locação Social, desenvolvido pela prefeitura paulistana para subsidiar habitações produzidas pelo município. Esse programa foi criado em 2002 e regulamentado pela Instrução Normativa - Sehab/G n. ${ }^{\circ}$ 001/03, de 07/05/2003, com o objetivo de oferecer atendimento por meio de aluguel social, em unidades novas ou requalificadas para famílias com renda de até três salários mínimos. É aplicado nas áreas centrais da cidade, visando à requalificação urbanística.

52 SACHS, Ignacy. Desenvolvimento includente, sustentável sustentado. Rio de Janeiro: Garamond, 2004, p. 14.

53 SACHS, Ignacy. Desenvolvimento includente, sustentável sustentado, p 14. 
Do ponto de vista da percepção dos idosos, as despesas que desembolsam para custear a moradia condizem com a condição financeira de cada morador, reforçando a viabilidade econômica do projeto.

A dimensão social é a mais expressiva nesse caso, tendo em vista que a Vila dos Idosos possibilita a inclusão e integração socioespacial dos moradores na cidade. A existência de uma biblioteca municipal na mesma área do conjunto habitacional é outro fator que revela a dimensão social. Essa aqui é a que propulsiona o equilíbrio dinâmico entre as outras dimensões. Para Sachs, a social é "fundamental por motivos tanto intrínsecos quanto instrumentais, por causa da perspectiva de disrupção social que paira de forma ameaçadora sobre muitos lugares problemáticos do nosso planeta"54. Levando em consideração demandas, peculiaridades, potencialidades e limites da pessoa idosa no espaço urbano que se pretende democrático e igualitário, é preciso desenvolver estratégias e formular/implementar políticas públicas, como essa alternativa encontrada pelo GARMIC:

A "Vila dos Idosos" é um exemplo de política pública que deu certo. A presença de profissionais com perfil para atender aos moradores, a rede de serviços disponíveis, são estes fatores determinantes para o sucesso do programa. Assim os idosos da Vila são tratados com respeito, mantendo a autonomia e a vida digna ${ }^{55}$.

Acrescente-se ainda a superação de uma crítica de Sen (2004) à definição das "necessidades" das presentes e futuras gerações, no sentido de que as pessoas não são somente pacientes com necessidades, mas agentes de suas próprias vidas, daí a importância dada aos valores que as pessoas têm. E um desses valores é exatamente a capacidade de agir em seu próprio benefício e da coletividade, como ilustra a experiência citada. Nesse sentido, reconhece-se a Vila dos Idosos como um conjunto habitacional sustentável, sendo certa a sua contribuição para minimizar a problemática habitacional vivenciada pelo grupo etário acima de 60

54 SACHS, Ignacy. Desenvolvimento includente, sustentável sustentado, p. 14.

55 DEUS, Suelma Inês Alves. Um modelo de moradia para idosos: o caso da Vila dos Idosos do Pari-São Paulo (SP). Caderno Temático Kairós Gerontologia, São Paulo, v. 8. p.195213. Disponível em: <http://revistas.pucsp.br/index.php/kairos/article/view/6922/5014>. Acesso em: abr. 2012. 
anos de baixa renda. É uma tipologia que deve ser mais difundida pelas cidades brasileiras, pois atende à acessibilidade, regulamentada na legislação brasileira e destacada nos eixos do Projeto Cidade Amiga do Idoso da OMS.

\section{CONSIDERAÇÕES FINAIS}

Com o novo quadro da longevidade humana que se delineia para os próximos anos, novos desafios permeiam ambientes urbanos realmente sustentáveis. A questão da inserção equitativa do idoso precisa ser definitivamente enfrentada para a consolidação do direito à cidade. Políticas públicas que propiciem moradia digna é o primeiro passo para que outras políticas se realizem no sentido de propulsionar a mobilidade urbana e social.

Nesse cenário, é preciso otimizar o envelhecimento ativo e saudável para que os próprios cidadãos implementem as dimensãos da sustentabilidade, ao mesmo tempo que reforcem o sentido de pertencimento ao local que habitam.

Para tanto, se faz necessária mudança de atitude, tanto do poder público quanto da sociedade, que deverá se organizar para reconhecer as demandas e criar alternativas inteligentes e acolhedoras que impulsionem a inclusão e a integração socioespacial.

Os movimentos sociais, como o GARMIC, desempenham papel preponderante nesse sentido, a exemplo da construção da Vila dos Idosos. Nascida da articulação de pessoas com mais de 60 anos reunidas para pressionar o poder público e mobilizar a sociedade a respeito da problemática habitacional vivencidada, especialmente por determinados grupos sociais de baixa renda. O GARMIC continua atuando e trabalhando no processo de pós-ocupação, considerado relevante quando se fala em sustentabilidade e em pertencimento do cidadão ao local, incentivando novas práticas análogas a essa.

Além do protagonismo do idoso, o poder público municipal que aderir à implementação dos eixos da Estratégia Cidade Amiga do Idoso - OMS, possibilita um espaço urbano mais sustentável, na medida em que prioriza ações tendentes a melhorar a acessibilidade, sinônimo de equidade e justiça social, ultrapassando a questão habitacional e instigando a gestão participativa e democrática da cidade. 
Ao implementar práticas sustentáveis no espaço urbano, é imprescindível o reconhecimento da necessidade da promoção do envelhecimento ativo e saudável.

\section{REFERÊNCIAS}

ACSELRAD, Henri. A duração das cidades: sustentabilidade e riscos nas políticas públicas. Rio de Janeiro, 2001.

ALFONSIN, Betânia de Moraes. In: MATTOS, Liana Portilho (Org.) Estatuto da Cidade Comentado. Belo Horizonte: Mandamentos, 2002.

BONDUKI, Nabil. $O$ modelo de desenvolvimento urbano de São Paulo precisa ser revertido. Disponível em: http://www.scielo.br/scielo.php?pid=S0103-40142011000100003\&script=sci arttext. Acesso em: jul. 2014.

BRASIL. Constituição da República Federativa do Brasil de 1988. Disponível em: < http:// www.planalto.gov.br/ccivil_03/constituicao/constitui\%C3\%A7ao.htm> Acesso em: out. 2010. BRASIL. Lei n 10.257, de 10 de julho de 2001. Dispõe sobre o Estatuto da Cidade e dá outras providências. Disponível em: http://www.planalto.gov.br/ccivil_03/leis/leis_2001//10257.htm. Acesso em: mar. 2013.

BRASIL. Lei $\mathbf{n}^{\circ} \mathbf{1 0 . 7 4 1}$, de 1 de outubro de 2003. Dispõe sobre o Estatuto do Idoso e dá outras providências. Disponível em: http://www.planalto.gov.br/ccivil_03/leis/2003/10.741. htm. Acesso em: mar. 2012.

BRASIL. Ministério das Cidades. Conferência Nacional das Cidades. Propostas de prioridades para o Ministério das Cidades. Disponível em: http://www.cidades.gov.br/5conferencia/ images/arquivos/propostas-prioridades-MCID.pdf. Acesso em jul-2014.

BRUNTDLAND, G. H. Our souls are tôo long for this short life. Sustainable Developmentinternational, London, 1999. Disponível em http:// www.sustedev.org. Acesso em: 06 nov. 2011.

CAMARANO, Ana Amélia. Envelhecimento da população brasileira. In: FREITAS, E.V. et al. Tratado de geriatria e gerontologia. Rio de Janeiro: Guanabara Koogan, 2011. p.58,73.

DEBERT, Guita Grin. A reinvenção da velhice. São Paulo: EDUSP, 1999. 
DEUS, Suelma Inês Alves. Um modelo de moradia para idosos: o caso da Vila dos Idosos do Pari-São Paulo (SP). Caderno Temático Kairós Gerontologia, São Paulo, v. 8. p.195-213. Disponível em: <http://revistas.pucsp.br/index.php/kairos/article/view/6922/5014>. Acesso em: abr. 2012.

ESPANHA, Lei 01 de 26 de julho de 2005. Por el que se aprueba el texto refundido de La ley de Urbanismo.

ESPANHA, Lei 39 de 14 de dezembro de 2006. Dispõe, de Promoción de la Autonomía Personal y Atención a las personas en situación de dependencia.

FERNANDEZ, Fernando. Aprendendo a lição de Chaco Canyon. Revista Reflexão, Instituto Ethos, São Paulo, 2001.

FRANÇA Fo, Genauto Carvalho; SANTANA Jr. Gildásio. Economia Solidária e Desenvolvimento Local: uma contribuição para redefinição da noção de sustentabilidade a partir da análise de três casos na Bahia. Disponível em: http://ites.colivre.net/pub/Site/Publicacao4/07genautolocal. pdf. Acesso em nov de 2010.

FRANCE, Conceil National des politiques de lute contre La pauvreté et l'exclusion sociale. Loi 2000-1208 du 14 décembre 2000 relative à la solidarité et au renouvellement urbain (SRU). Disponível em: http://www.cnle.gouv.fr/Loi-2000-1208-du-14-decembre-2000.html. Acesso em: jun. 2014.

INSTITUTO BRASILEIRO DE GEOGRAFIA E ESTATÍSTICA - IBGE. Censo 2010: população do Brasil é de 190.732.694 pessoas. Disponível em: http://www.ibge.gov.br/home/presidencia/ noticias/noticia visualiza.php?id noticia $=1766$. Acesso em mai. 2012.

KALACHE, Alexandre et al. O envelhecimento da população mundial: um desafio novo. Revista Saúde Pública, São Paulo, v. 21, n. 3, jun., 1987. Disponível em: < http://www.scielosp.org/ scielo.php?pid $=$ S003489101987000300005\&script $=$ sci arttext $\&$ tIng $=$ ptpt $>$. Acesso em: out. 2011.

LA PUERTA, Belén Morata García. Cuestiones para investigación: ¿qué pasa con los servicios sociales en España? Serviço Social e Sociedade. no.108. São Paulo Oct./Dec. 2011. Disponível em: < http://www.scielo.br/scielo.php?pid=S0101-6282011000400002\&script=sci abstract\&t|ng=pt>. Acesso em: jul. 2012.

LOFQVIST, Charlotte; GRANBOM, Marianne; HIMMELSBACH，Ines; IWARSSON, Susanne; 
OSWALD, Frank; HAAK, Maria. Voices on relocation and aging in place in very old age - a complex and ambivalent matter. The Gerontologist. V. 53, no.6, p. 919-927, 2013.

MENDES, Judas Tadeu Grassi. SILVA, Christian Luiz da. Reflexões sobre o desenvolvimento sustentável: agentes e interações sob a ótica multidisciplinar. Petrópolis: Vozes, 2005.

MILARÉ, Édis. Direito do ambiente. São Paulo: Revista dos Tribunais, 2009.

MONTEIRO, L. C. A., Políticas Públicas Habitacionais Para Idosos: Um estudo Sobre os Condomínios Exclusivos. 2012. 145f. Tese (Doutorado em Engenharia Urbana) - Programa de Pós Graduação em Engenharia Urbana UFSCar. Universidade Federal de São Carlos, São Carlos.

MOSLER Enrique Rajevic. El palatino pero insuficiente desarollo Del Derecho urbanístico em Chile: em tánsito de La adolescência a La madureza. In FERNANDES, Edésio, ALFONSIN, Betânia. Forum de Direito Urbano e Ambiental. Belo Horizonte: Forum, 2010, pg 61,70, n. 54.

NERI, Anita Liberalesso. Idosos, velhice e envelhecimento. In: Neri, A.Palavras-chave em Gerontologia. 3. ed. Campinas, SP: Editora Alínea, 2008. p. 114-115. (Coleção Velhice e Sociedade).

NOBRE, Marcos, Desenvolvimento sustentado e problemática ambiental. In Lua Nova Revista de Cultura e Política. Disponível em: <http://www.scielo.br/scielo.php?pid=S010264451999000200008\&script=sci_arttext >. Acesso em: mai. 2013.

ONU - ORGANIZAÇÃO DAS NAÇÕES UNIDAS. Nova York, ONU discute desafios populacionais do planeta, 20 anos após conferência sobre tema. Disponível em: http://www.onu.org.br/ em-nova-york-onu-discute-desafios-populacionais-do-planeta-20-anos-apos-conferenciasobre-tema/. Acesso em jul-2014

ONU - ORGANIZAÇÃO DAS NAÇÕES UNIDAS / PNUD - PROGRAMA DAS NAÇÕES UNIDAS PARA O DESENVOLVIMENTO. Desenvolvimento humano e IDH. Disponível em < http:// www.pnud.org.br/idh/>. Acesso em: 19 ago 2011.

ONU - ORGANIZAÇÃO DAS NAÇÕES UNIDAS. Rio + 20 Conferência das Nações Unidas sobre Desenvolvimento Sustentável. Disponível em: http://www.onu.org.br/rio20/temascidades/. Acesso em: maio de 2013.

ORGANIZAÇÃO MUNDIAL DA SAÚDE - OMS. Guia global das cidades amigas das pessoas idosas. 2009. Versão traduzida para o português. Disponível em: <http://whqlibdoc.who.int/ publications/2007/9789899556867_por.pdf>. Acesso em: jun. 2011. 
PAPALÉO NETO, M. O estudo da velhice: histórico, definição do campo e termos básicos. In: PAPALÉO NETO, M. Tratado de gerontologia. 2. ed. São Paulo: Editora Atheneu, 2007. P.29,38.

PINHEIRO, Naide Maria. Estatuto do Idoso Comentado. Campinas: Servanda, 2008.

PRADO, Adriana Romeiro de Almeida; PERRACINI, Monica Rodrigues. A construção de ambientes favoráveis aos idosos. In: NERI, A. Qualidade de vida na velhice. Campinas: Alínea, 2011.

SACHS, Ignacy. Desenvolvimento includente, sustentável sustentado. Rio de Janeiro: Garamond, 2004.

SÃO PAULO (Estado). Ministério Público. Guia Prático: o direito de todos à educação: diálogo com os Promotores de Justiça do Estado de São Paulo/ Ministério Público do Estado de São Paulo. São Paulo: MP, 2011. 165 p.

SEN, Amartya K. Por que é necessário preservar a coruja-pintada. Folha de São Paulo, 14 de março de 2004. Disponível em http://www1.folha.uol.com.br/folha/ciencia/ult306u11316. shtml. Acesso em mar. 2013.

SILVA, José Afonso da. Direito Urbanístico brasileiro. São Paulo, Malheiros, 2006.

TEDESCHI Sebastian. Los conflictos urbanos en el territorio y el derecho en America Latina. In FERNANDES, Edésio, ALFONSIN, Betânia. Forum de Direito Urbano e Ambiental. Belo Horizonte: Forum, 2010, pg 17,37, n. 54.

UNITED NATIONS. Population Division of the Department of Economic and Social Affairs. World population prospects: the 2002 revision. Highlights. New York: United Nations, 2003.

VEIGA, José Eli da. Sustentabilidade: a legitimação de um novo valor. São Paulo: Editora SENAC, 2010.

Recebido em: jun/2013

Aprovado em: jul/2014 